\title{
What was the process and response of university staff and students to the availability of a shared reading scheme for those embarking on a university education? A case study
}

Alison Baverstock and Jackie Steinitz

\begin{abstract}
This paper reports and reflects on the processes and outcomes of a shared reading programme targeted at new students embarking on a university qualification at Kingston University. It isolates the various stages involved, from selecting a book for sharing to the despatch of a bespoke edition to new students and wider distribution within the institution. It then explores and assesses the effects the scheme had on the community, by role and department, through both informal measures of assessing impact and post-delivery surveying of those involved. Recommendations are offered for further development of the project.
\end{abstract}

\section{Key words}

Pre-arrival shared reading; Big Read; student and staff enrolment, engagement and retention.

\section{Background}

This paper, the second in an anticipated series of four, tracks the process of delivering a pre-arrival shared reading scheme at Kingston University. The first paper (Baverstock et al, 2016) outlined the research project conducted among first year students to explore their use of leisure time and their likely response to a reading scheme; the positive findings from this study led to the establishment of the first Big Read at Kingston University in September 2015. This paper now outlines the logistics of setting up and running the scheme, then reports on informal and formal measures of the reactions by the staff and students to that experience.

\section{Literature review}

The previous paper identified the main research which supports pre-arrival shared reading schemes. In essence there are two main streams. Firstly there is significant evidence of the benefits of reading for pleasure, which is associated with a range of life-positives such as greater safety, health, income, professional success, articulateness, empathy and happiness. This has been consistently reported, but most recently in an extensive study undertaken by The Reading Agency and BOP Consulting (2015).

Secondly there is literature relating to the development of shared reading schemes in US universities and particular parts of the process. There is a common thread in such schemes that students are reported to be more likely to enrol, feel engaged early, less likely to drop out and feel more connected locally. While there is some analysis of the outcomes of pre-arrival shared reading in the US, for example, Ferguson (2006) and Golden (2012) both discuss the role such schemes can play in widening participation and promoting engagement, and Twiton (2007) concluded a successful outcome from the qualitative comments of those who did provide feedback; the numbers of those who attended related events and the anecdotal feedback from those involved. It was anticipated that taking part in pre-arrival shared reading would tend to confirm students' decision to enrol and turn up. However much of the reporting back on the outcomes of pre-arrival shared reading in universities (see the list of websites in the bibliography) is general and used for promotional information rather than being subjected to academic scrutiny. This project therefore sought to 
redress this gap in the literature, and to analyse responses/identify outcomes by students and staff as the first stage of a longer term research project with wider possibilities for collaboration.

\section{Project development}

The project was undertaken as part of SADRAS, (Student Academic Development Research Associate Scheme), a Kingston University scheme that is funded through the University's Access Working Group. Collaboratively managed by the Kingston University Students Union (KUSU) and the Centre for Higher Education Research and Practice (CHERP), this project is also the first step in a wider effort to build a partnership that ensures that students and staff are equal, engaged partners in an academic community that drives forward learning, teaching, research, and innovation. SADRAS offers academics and students the chance to work together in pursuit of a project that benefits the achievements, progression, and retention of one or more of the following groups of students who have not traditionally thrived at university: ethnic students from ethnic minorities; first-generation students; mature students; students who have responsibilities as carers; and disabled students.

This particular project aimed to use shared reading to:

- breach any divide between those coming to Kingston from different backgrounds and walks of life

- enhance a sense of community among new students

- connect the five Kingston University faculties; administrative and academic staff - with students and with each other

- promote reading for pleasure, but to do this through a scheme appealing to all, without making any group feel particularly targeted or stigmatised

Following positive feedback from the initial research conducted on first year students in Spring 2015 (Baverstock et al, 2016) a decision was made to offer the scheme (The Kingston University Big Read) to all incoming students in September 2015. A book on which the scheme could be based was therefore urgently required, and since there was not time to organise wider organisational consultation and as there was a strong desire by the particular students who had planned the initial research to see through the delivery of the first reading scheme, Nick Hornby's About a boy was selected following a recommendation by the Vice Chancellor, Professor Julius Weinberg. Nick Hornby is a graduate of Kingston University, his books have broad appeal and this book was considered particularly suitable as it is about transition and growing up, it is set in London and is an accessible read for all ages and genders.

The KU Big Read was given a budget and permission to access various university services. A logo was devised by the university communications team and a budget allocated for the purchase of books. A special edition was commissioned from Penguin Random House bearing the scheme logo on the front, information on the university on the back cover, a letter from the Vice Chancellor on the first two pages and a series of 'book club' style questions in the back. This was sent to all arriving firstyears, at both under- and post-graduate level and also made available to all staff who wanted to participate. 


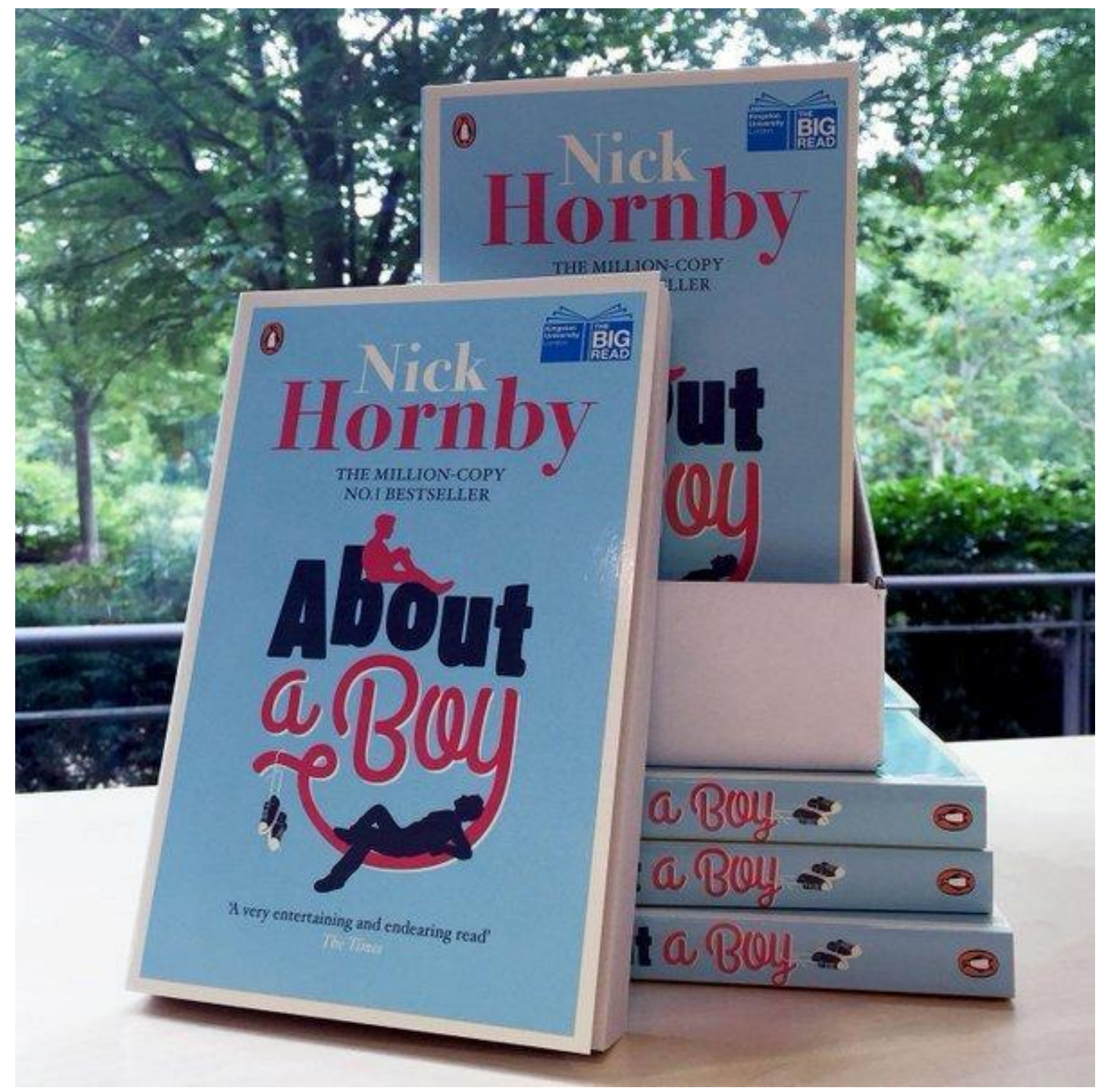

Special 'Kingston' edition of Nick Hornby's About a boy, co-produced with Penguin Random House.

The book was sent out by various means. The contact data for all new students in the UK and Europe was sent securely to a local mailing house and the book was sent to the home addresses of the intended students from the UK and Europe in three tranches. Firstly it was sent to those who had a firm offer, in mid-August 2015. Secondly it went to those who had met their conditional offer, once the ' $A$ ' level results were out in late August; significantly the mailing was despatched immediately after the results were announced, thus after these students had met their offer but before they had accepted their place, with the intention of influencing their decision. Thirdly it was sent to those who had accepted a place through clearing.

The mailing was despatched in a polylope (plastic envelope) with the front cover of the book clearly visible and University branding on the reverse. It included a covering letter from the author, talking about his own feelings when about to embark at university, and on the reverse was a list of events 
connected to The KU Big Read that would be run in the first weeks after arrival - as well as a link to online opportunities to share connected ideas. The book was made available to international students as part of their welcome pack, distributed on arrival at the start of their pre-induction week.

Bulk copies were sent directly to those running groups or schemes within Kingston University whose cohorts were likely either to benefit directly or who would be able to spread awareness of the scheme. Thus, for example, it was sent to those managing the University Mentors and Student Ambassadors for pre-semester training, the student engagement team and their Welcome Connectors and access groups supporting those from non-traditional backgrounds who receive presemester preparation through Head-Start and to students attending summer schools. It was also send to those working with pre-sessional English Language Course students:

'We work with at least 200 international and EU students preparing to study at Kingston. Last year and this year again we used the Big Read as a topic for a lecture (for students to practise listening and note-taking skills), stressed the value of reading as a way of developing language skills and gave out a copy to every student. Giving these students the book early gives them time to read it before the semester starts and Big Read activities begin in the University/ Faculties. Feedback from students made it clear they liked being given a free book, and liked the fact that they could potentially use it as a device to start conversation with home students.' Karen Hurley, Pre-sessional Course Director

These groups generally provided our first student feedback, which from the outset was very positive. We started hearing the book referred to as a 'present' or 'gift'; recipients told us they felt 'welcomed' and 'expected'. One girl confessed she'd been feeling nervous and found the arrival of her book 'comforting'.

The book was also made available to all staff who wanted to participate, with two specific objectives in mind. Firstly it was hoped that staff would read the book and then use it as a basis for conversations, and to this end it was made available to staff from early July onwards, hopefully in time for it to be taken on holiday. Secondly it was hoped that the book would be used by all staff as a means of linking with students, in informal discussions and welcome activities, and in planning the early weeks of teaching and formative assessment. A digital presentation to be used as a teaching resource in engaging discussions with students was circulated to staff who expressed an interest in the scheme.

How to engage staff was a strong consideration and the scheme consistently benefitted from the prior experience of various experts within the university. In the case of staff, the communications manager advised that giving staff a free copy of the university magazine, either through the post or inserting it in individual pigeonholes was likely to lead to a certain degree of resistance, and complaints that staff were being given something they had not asked for and, although sustainably produced, complaints about the resulting loss of trees. Knowing that the scheme attracted strong support from librarians, we therefore made the book available in libraries and reception desks throughout the university and asked staff who wanted a copy to collect one for themselves; thus requiring positive action on the part of staff who wished to be involved rather than distributing as a 'negative option', with no alternative but to receive. 
A variety of events were organised. The author came to Kingston as part of Kingston Connections ${ }^{1}$ and having been interviewed by the Vice Chancellor, the choice of his book for the forthcoming Big Read was announced and community participation invited. During the University's Welcome Week in late September, opportunities to discuss the book were scheduled for all campuses alongside discussions of study skills, workload planning workload, opportunities for volunteering and paid work, and how to cook. During the week the author visited the University, gave a short interview and then answered their questions.

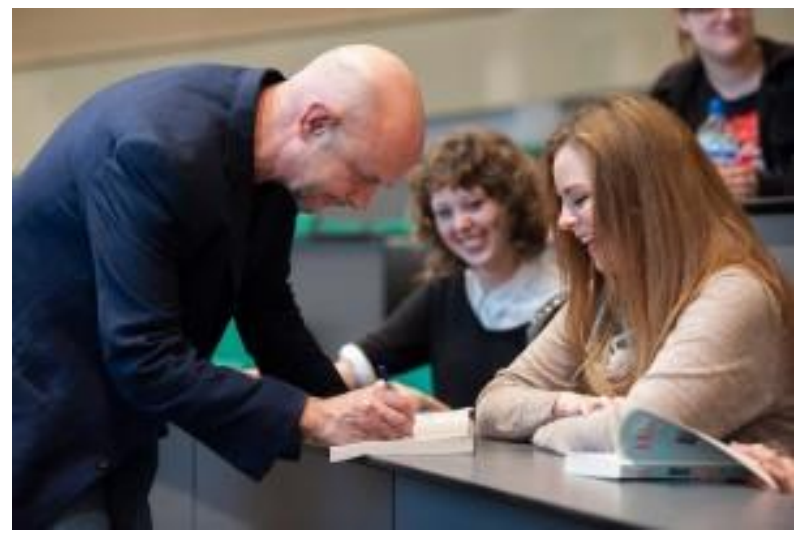

Nick Hornby signs his book for students and staff. Credit: Ezzidin Alwan/Kingston University London

A 'balloon debate', chaired by the University Chancellor, Bonnie Greer, was held in late October at which staff shared their thoughts on how the themes of the book related to their professional and personal interests. Examples included a member of the Reception Team talking about how the book was used in welcoming new students and visitors to the university; a lecturer from Social Work talking about the safeguarding issues raised by the book; a lecturer from English Literature talking about the responsibilities and associated processes for choosing titles for students to read and a lecturer from Pharmacy considering the various substances used during the book.

'Thank you so much for this. It was genuinely fascinating to hear so many different views, and from right across the university. It was so unexpected to hear how different individual responses to the same material can be.' Nona McDuff, KU's Head of Diversity and Inclusion, October 2016

\section{How to measure the outcomes of the project}

A variety of informal and formal means were used to attempt to evaluate its success. There were some simple measures for evaluation: for example, how many books were printed; how many were

\footnotetext{
${ }^{1}$ Civic engagement programme run 2012-2015 involving a collaboration between Kingston University, The Royal Borough of Kingston, Creative Youth (founders of the International Youth Arts Festival) and The Rose Theatre, Kingston, where events were held. The contribution of the University was a series of staff members giving presentations about their research and interests, and in this context the author Nick Hornby was interviewed by the Vice Chancellor, Professor Julius Weinberg.
} 
left over afterwards? But what was really sought was information on how engaged were students and staff, and how it could be known whether this was an initiative worth repeating.

\section{Informal assessments of the effectiveness of The KU Big Read}

Early reaction to the project could be seen from the informal activities and responses of students and staff.

\section{Initial response to the physical object bearing the University branding.}

There was significant traffic on social media reporting receipt, commenting on associated pleasure, and taking part in an Extreme Reading competition which asked participants to share an image of the title being read in unusual circumstances. There was extensive discussion on Facebook. Students consistently reporting positively on having received a 'present' or 'gift' from 'their university' before they had even arrived. They talked about finding the experience of receipt 'welcoming' and 'comforting' and the pleasure of finding themselves 'expected'. Several students reported that that their parents were so intrigued by the package that they opened it.

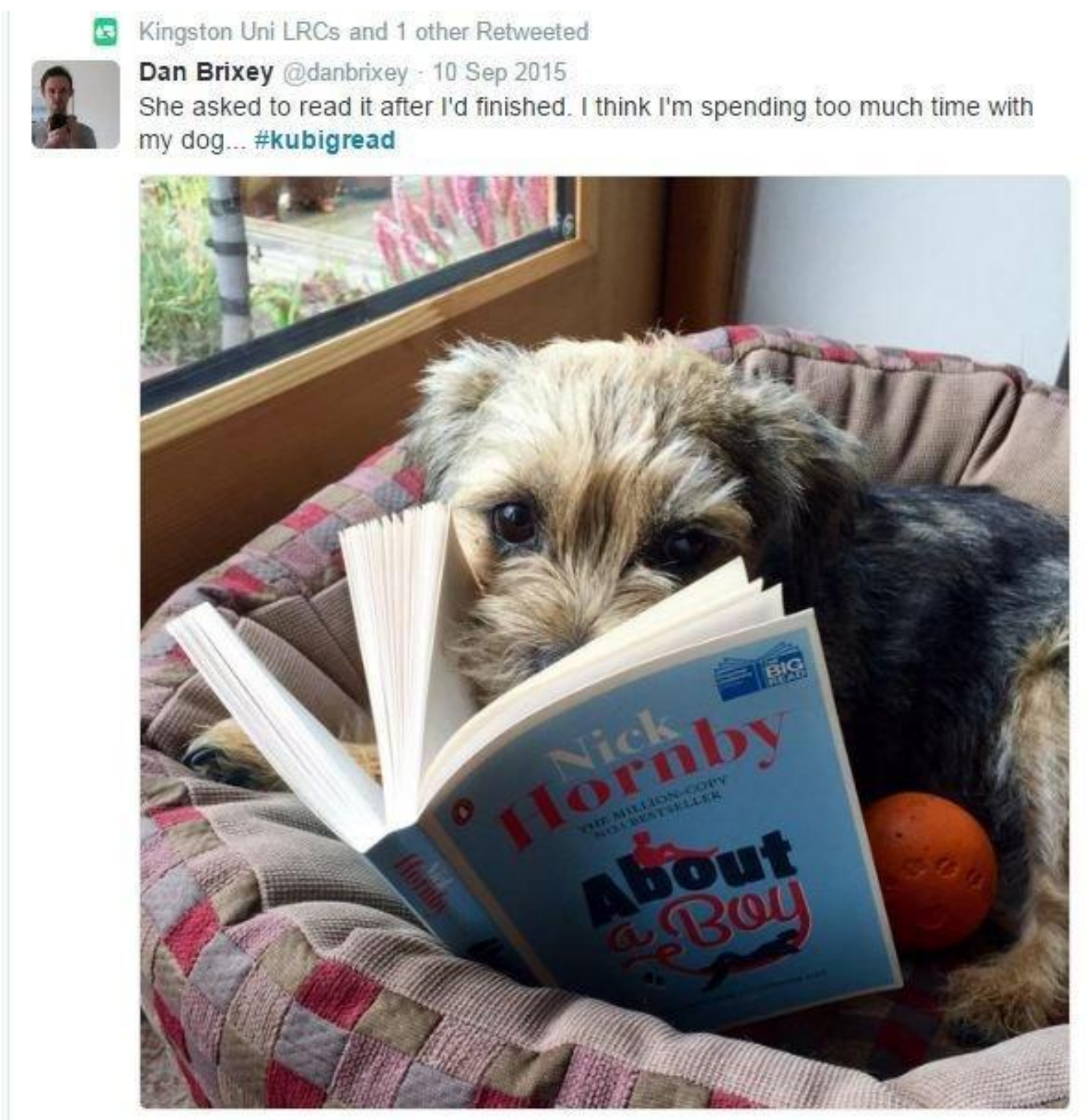




\section{Heavy demand for copies of the book}

The initial print run of 10,000 ran out quickly and two subsequent reprints were required. Reception desks and the libraries regularly reported needing more stock. The ethical disposal policy for unrequired copies (distribution to schools and delivery to the local Oxfam bookshop) was never needed; as soon as copies appeared they were removed. An informal measure of the value placed on the item (reported by a member of the library team, based on her experience) was the fact that no stock was left lying around, or spotted in waste paper and recycling bins.

\section{Attendance at related events.}

Short (50 minutes) sessions about the book were run during Welcome Week on every campus, offering the opportunity for students to talk both about the book and about the experience of prearrival shared reading. There was very positive feedback from those who attended, and more anecdotal appreciation of receiving a present before they had arrived. Students attending were monitored (how many attending each event; 'useful'/'not useful' voting; qualitative feedback via 'post-it' notes) - and extremely positive responses were recorded.

Also within Welcome Week, an event with the author was organised. Attendance was high; the lecture theatre was packed. Those asking questions were asked to state their department before asking questions, and it was clear that the information on the event had spread across the institution and appealed to students from a wide range of disciplines. Afterwards the author signed copies of his book for over an hour.

The scheme had a stand at the Freshers' Fayre held at the end of Welcome Week. Again, the response was highly positive. In a sea of stalls offering free food, branded items and the opportunity to sign up for additional activities, the stand for The KU Big Read was simple - books on offer. Students wandering past did a double-take on seeing the books, and talked again, often at some length, about how much they had appreciated their 'present'.

\section{The initial response from staff}

After the initial research on the student intake of 2014 (Baverstock et al, 2016) the positive student response was expected and not a surprise. There was no pre-indication however of the staff response. In the event there was high staff engagement from all functions and roles, across the University who both took a copy of the book and reported associated development of their own activities. For example, the University HR department began to use the book in staff induction, giving a copy to all new colleagues. Both Finance and Estates departments asked for bulk copies of the title to use as part of a team-building exercise. The team manning reception desks throughout the university were fully engaged and used the book to start conversations with those who were visiting, or with staff with whom they had regular but shallow contact (e.g. those collecting guests from reception). Staff from the Learning Resource Centre were reported to be telling students and staff that our bespoke version had added value as a 'limited edition', and one of the cleaning team was heard recounting, with some satisfaction, that the project had been developed in 'her area' of the building. Such was the demand from staff that it was necessary to twice order a reprint, and in total 13,000 books were purchased and distributed across the organisation.

LRC staff were particularly keen and, unasked, they embedded the scheme in both their internal information channels and in opportunities for interaction with academic systems. For example, 
About a Boy was used as the Learning Resource Centre's example for how to find a book in the library, and raised as an agenda item by librarians in Boards of Study and staff-student meetings.

The scheme attracted measurable interest from the university's own online monitoring (e.g. the River Online - the KU student newspaper and tracked social media on Facebook and Twitter). The scheme was also featured by the collaborating publishers, Penguin Random House, as an example of an effective partnership (Penguin, 2015) and by the The University Alliance as an example of an innovative research campaign that was measuring, and therefore had the potential to improve, its impact:

'What a fantastic - and positive - story this is on how a book can change a campus and help create a community' Gabriel Huntley, Head of Communications and External Relations, University Alliance

The University Alliance twice featured blogs on the scheme (Frostick, 2015; Baverstock 2016) and featured the project several times in its email updates and a presentation on The KU Big Read was invited for their Conference of Member Heads of Communication, July 2016.

Kingston staff were asked to monitor how they used the scheme and a list was kept. Staff were asked to monitor the response they got, whether loosely in terms of engagement/feedback/questions or precisely in terms of class lists/attendance. Some discussed the title with their classes, for example:

'I teach courses that can be quite 'heavy' in their course structure, list of topics and the associated reading material, for example considering human rights or national security policies. And so to have something less weighty to break the ice, and most of all that does not relate to those things, was very useful in the initial stages, in order to build up some kind of rapport with the students.' Pete Finn, Lecturer in Politics, Kingston University

Others used it in specific teaching situations:

'I used The Big Read in the final year MPharm project module and with my research students in general, both undergraduate and postgraduate. When I am guiding and supporting my research students in their dissertation writing, I always recommend that it needs to flow well, and the sections need to be connected, and getting the students to consider Nick Hornby's About a boy, the first KU Big Read, was a good way of engaging them in this process. We talked about how the book began - and made you want to keep reading - and how the narrative develops. I encourage them to tell the story, for example, how does this background literature review lead up to your research rationale and the overall aim?

I used novel reading to inform students of how to introduce the characters (concepts and events); how to structure their sentences in succinct fashion; how to write events and literature in chronological order. I also talk to them about what makes a book an 'easy read' and what does not, so that they consider the reader in their writing style. The reader should not need to flick pages backwards and forwards to understand the sequence of events. The reader will definitely lose interest, if events appear out of nowhere; without a good lead to 
that event, for example the results chapter. I also used the book in helping them construct the conclusion as it needs to bring an end while also bringing all facts/aspects together. Nick Hornby books are examples of simple-read and easy to follow books, which can be enjoyed by people from a variety of different levels of understanding. Scientific writing should also be able to address and reach all levels of people too, especially as markers and grant reviewers in health can be non-expert in the field - and for the latter can be lay members of the public. Finally I used the Big Read to promote the University in open days and in induction events as a course director.' Professor Reem Kayyali, Department of Pharmacy, Kingston University

or found it enriched relationships with colleagues:

'The balloon debate was a very interesting experience for me. It inspired me to explore the book through a pharmacist lens focusing on the medicines used in the suicide and the overall national statistics of completed suicides in England. Taking part also highlighted to me what other colleagues saw in the book that I missed. For example: depression in middle aged men. There was a richness in the exposure to other peoples' exploration of the book which I found fascinating, and I feel very privileged to have been part of it.' Shereen Nabhani-Gebara, PharmD, BCOP, Senior Lecturer, Interprofessional Education Lead, School of Pharmacy and Chemistry, Kingston University.

\section{Formal Survey of Staff and Student Reactions to the Big Read}

In addition to the informal measures, a formal online survey was also conducted to gauge staff and student reaction to the scheme. The staff questionnaire was circulated in October with responses received from $15^{\text {th }}$ October to $3^{\text {rd }}$ November. The student survey was sent out in December 2015 with responses received from $7^{\text {th }}$ December to $9^{\text {th }}$ January. The two surveys were similar though not identical. In all 236 staff and 193 students responded, representing $11 \%$ and $3 \%$ respectively of the universes approached. These response rates were disappointing and there were important learnings about the timing and method for distributing the questionnaires next time. Nonetheless the sample was well distributed across age groups, ethnicity, faculty and role and it was felt that the surveys offered some useful findings and insights.

From the responses received, five key findings from the survey are now summarised considering: staff and student attitudes to reading; the distribution of the book; what staff and students did once they received the book (in terms of their involvement in reading it, discussing it and attending events); their verdict on the book; their verdict on the initiative as a whole.

\section{Attitudes towards reading are positive. Staff and students like reading for pleasure}




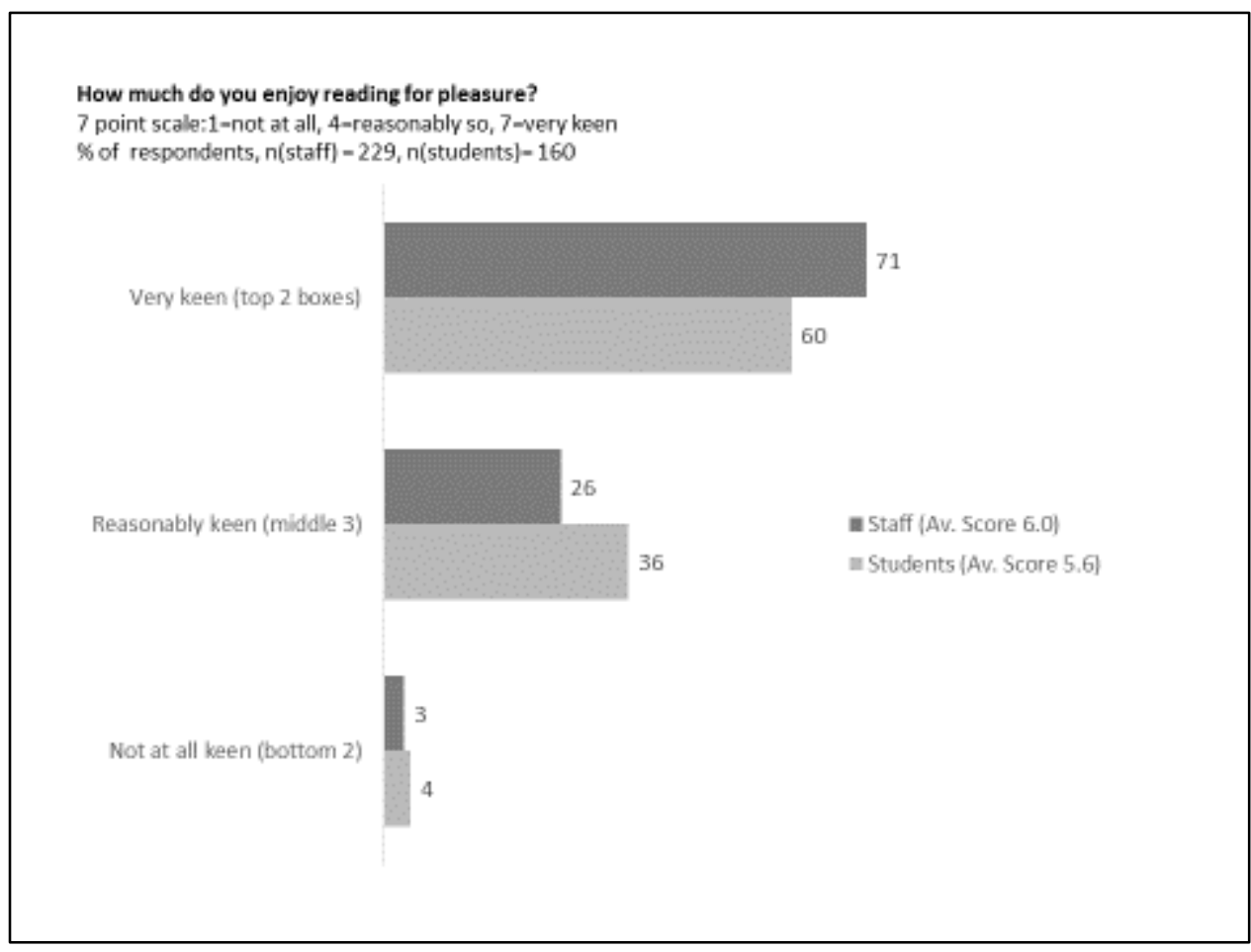

Figure 1: How much do respondents enjoy reading for pleasure?

When asked how much do you enjoy reading for pleasure on a 7 point scale (where 7 means very keen and 1 not at all) both staff and students respondents were mostly very positive with the staff score averaging 6.0 and students 5.6 (the slightly higher staff score may reflect the fact that the staff respondents would have been those who had actively chosen to pick up a book from a distribution point whereas the students had been sent one). This positive response confirmed the findings of the pre-scheme research, though these figures are higher that would have been expected from the national press, where it is often assumed that reading for pleasure is a dying pursuit. (Markoff, 2008) When the ratings are further broken down by various demographics it can be seen that this pleasure is shared across the board 
How much do you enjoy reading for pleasure?

Average Score, 7 point scale: $1=$ not at all, $4=$ reasonably so, $7=$ very keen (number of respondents)

\section{Students}

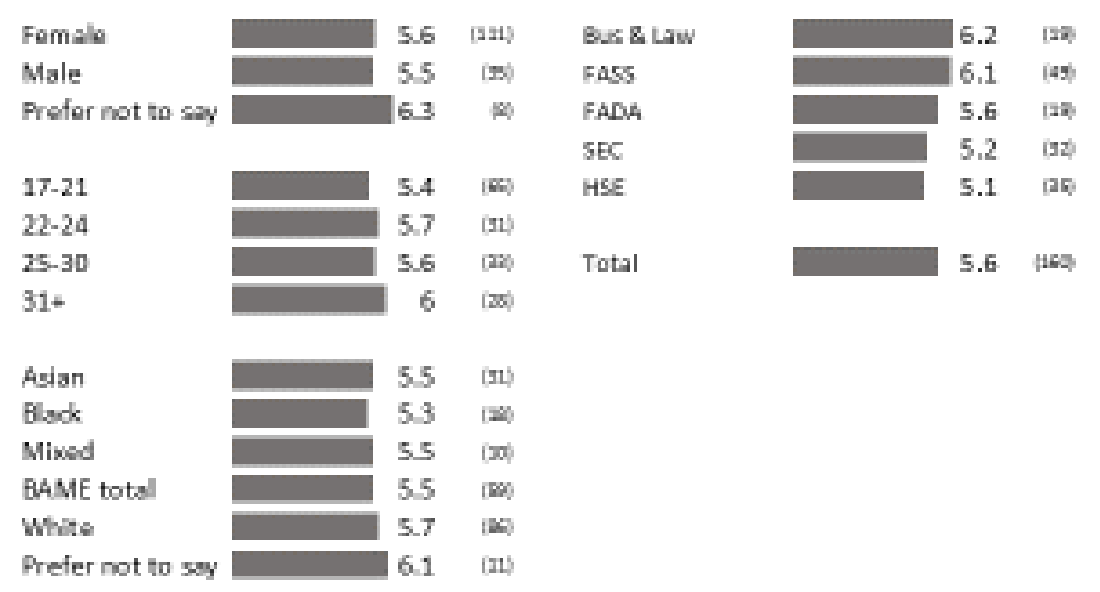

Staff

\begin{tabular}{|c|c|c|c|c|c|}
\hline Female & 6.2 & {$[24)$} & Student Services & 5.6 & [a \\
\hline Male & 5.6 & (n) & Library Services & 16,4 & 124 \\
\hline \multirow[t]{2}{*}{ Prefer not to say } & 6.2 & $\infty$ & Finance & 6.4 & [29 \\
\hline & & & FADA & 6.2 & 128 \\
\hline Under 30 & 5.9 & $(23)$ & Buxinss \& Law & 6.2 & 42 \\
\hline $31-40$ & 60 & 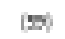 & W's advisory & 6.1 & las \\
\hline $41-50$ & 5.7 & {$[\mathrm{Ex})$} & Kusco & 6.0 & 129 \\
\hline $51-60$ & 162 & (7) & FASS & 6.0 & (195) \\
\hline $61+$ & 60 & (x) & SEC & 5.7 & an \\
\hline Prefer not to say & 16.3 & $(x)$ & $\pi$ & 5.0 & (20) \\
\hline LRC staff & 6.4 & (2) & Total & 6,0 & $\mid 225$ \\
\hline Academic staff & 6.1 & {$[\mathrm{es}$} & & & \\
\hline Admin staff & 60 & $(n 0)$ & & & \\
\hline Other staff & 5.7 & $(27)$ & & & \\
\hline Contracted staff & 5.2 & (34) & & & \\
\hline
\end{tabular}

Figure 2: How much do respondents enjoy reading for pleasure, students and staff, broken down by gender, age, ethnicity, faculty (students) or department and role (staff)

\section{Distribution of the titles was mostly successful, with some important learnings for project delivery another time}

Distribution of the titles was mostly successful, though with some important learnings for project delivery another time. 74\% of staff respondents picked up a book themselves, either from a Learning Resource Centre (LRC, commonly known as the library), a reception desk, a departmental office or from another person. Most found it easy to access a copy (average score 4.3 out of 5 on 'How easy 
was it to access a copy?') - but learnings include the need to ensure availability everywhere is timed with announcement and to ensure all receptions are covered.

$89 \%$ of student responders received a copy, including $72 \%$ who received it by mail to their home address, while the remainder got one at an International Student or Welcome Week Event or at an LRC. Those least likely to have received a copy were the older students (19\% of those aged $25-30$ compared with $6 \%$ of 17-21 year-olds). There were several instances of students reporting that a book had been received at their home address, but the package had been opened by their parents who were eager to see the book inside, and discussion of both project and book at home was an important side effect of the project as a whole.

The students were mostly very happy to receive a book. Asked to rate how they felt about receiving a free book from Kingston University within a seven point scale from 1 (indifferent) to 7 (very pleased), $84 \%$ pronounced themselves to be very to moderately pleased (scoring 4 or more out of 7 ). The average score was 5.2 .

In addition to grading their response on a seven point scale, from indifferent to very pleased, the survey offered them the option to add additional comments. These were predominantly positive, and included:

'Ideal choice and aided in boosting future students' feeling about moving internationally to attend Kingston. Such a well-known alumnus - impressive!'

'I thought it was a nice idea to have something in common with other students.'

'It made me feel special that I was seen as part of the university moving forward.'

'As a student whose degree involves books I felt like l'd picked the right university.'

'Very positive about attending Kingston university - brilliant idea!'

'I was excited to meet others who had read it to discuss the themes.'

'I didn't receive a book before arriving in the UK, but I received in the first week. It was a

great start, to be honest.'

'If there is another big read please post books to current students too.'

'It made me feel welcomed and part of a community, before l'd even arrived on campus.'

'Receiving a book seemed to me like an inclusive event, creating a sort of shared experience for new students. It was very welcome.'

'I would have been a lot happier if I received it in time for the big read.'

'I didn't receive a copy and was quite disappointed that I never got one.'

\section{The book was widely read and discussed, and the events were well attended}

The majority of staff and student respondents who received the book, also finished it, although there were variations in the percentage finishing the book by demographic both for students and staff 


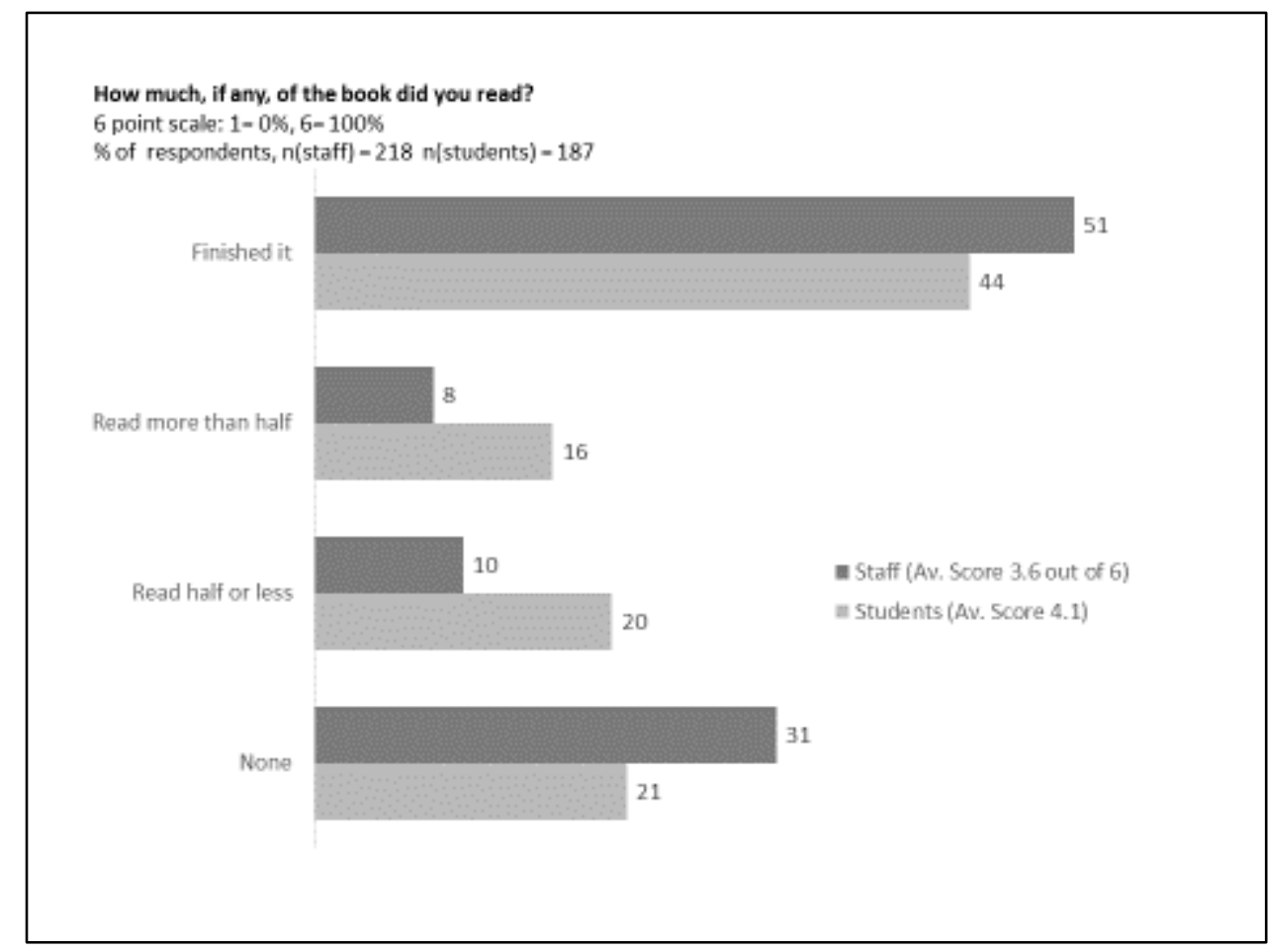

Figure 3: How much of the book did respondents read?

$\%$ of respondents who finished the book

Base: All those who received a book

(number of respondents)

\section{Students}

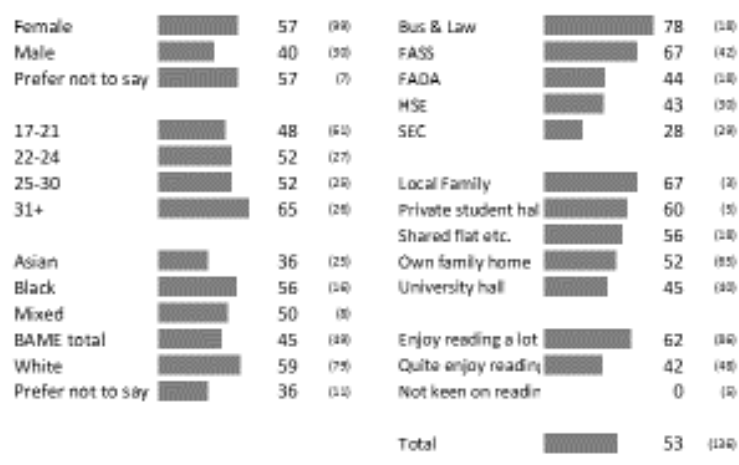

Staff

\begin{tabular}{|c|c|c|c|}
\hline Female & $E$ & 58 & $(22 \pi)$ \\
\hline Male & & 68 & (a) \\
\hline Prefer not to sor & 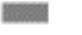 & 33 & $s$ \\
\hline Under 30 & 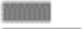 & 35 & (2a) \\
\hline $31-40$ & & 57 & (ax) \\
\hline $41-50$ & & 73 & (a) \\
\hline $51-60$ & & 69 & (6) \\
\hline $61+$ & & 50 & (2) \\
\hline LRC staff & & 80 & (24) \\
\hline Academit staff & & 62 & 35 \\
\hline Admin staff & & 61 & 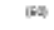 \\
\hline Other staff & & 48 & (25) \\
\hline Comtracted staff & & 30 & as \\
\hline
\end{tabular}

Enjoy resding s lot 68 (1220 Cuite ovioy readin $\quad 39$ and

Total 
Figure 4: The percentage of respondents who finished the book, broken down by broken down by gender, age, ethnicity, faculty (students) or department and role (staff), and by general attitudes towards reading.

There was a high level of discussion about the book. $73 \%$ of the student sample (and $60 \%$ of staff) discussed the book with others. Students were asked with whom they had discussed the book (with seven options for response: Student I live with; Student in my dept; Other student; Academic staff; Other KU staff; Family; Friends outside university). 17\% had discussed the book with three or more categories and a further $17 \%$ with two categories. $44 \%$ had discussed with another student, $38 \%$ with family and $32 \%$ with friends outside university

Those who had discussed the book with others mostly enjoyed the experience: $82 \%$ rated it somewhat to very enjoyable (allocating a rating of 4 or more out of seven).

$60 \%$ of staff respondents discussed the book with someone (33\% with a work colleague, $20 \%$ with family/friends and $6 \%$ with students). Staff who had picked up a book were most likely to discuss it (70\%) but a significant minority (26\%) of those who did not still had a discussion about it. Most likely to discuss the book were LRC staff $(81 \%)$, those who had finished the book (79\%) and staff under the age of $30(73 \%)$.

Again, discussion by staff was across most demographics, with slightly more women than men involved. 
$\%$ of respondents who discussed the book with someone

(number of respondents)

Students

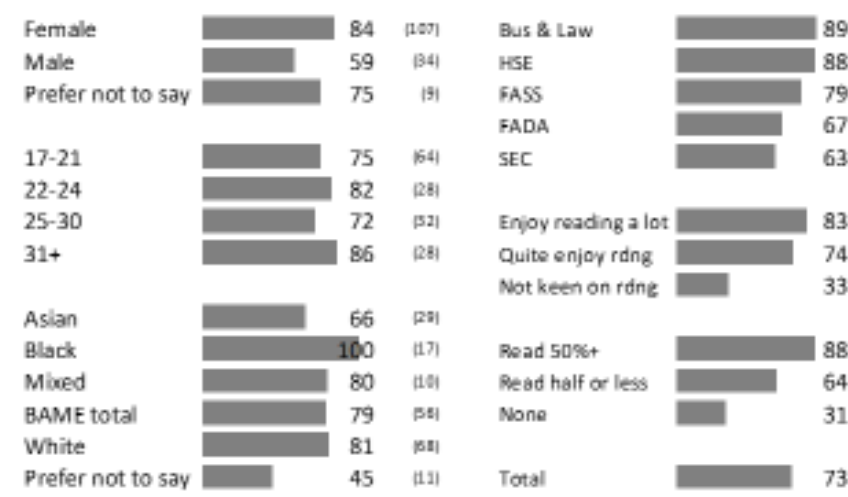

Staff

\begin{tabular}{|c|c|c|c|c|}
\hline Female & 64 & [14:] & Picked up a book & 70 \\
\hline Male & 55 & $|0 ;|$ & Did no pick up & 26 \\
\hline \multirow[t]{2}{*}{ Prefer not to say } & 56 & |6| & & \\
\hline & & & Read $50 \%$ t & 79 \\
\hline Under 30 & 73 & [221 & Read half or less & 71 \\
\hline $31-40$ & 56 & [55] & None & 22 \\
\hline $41-50$ & 69 & BDI] & & \\
\hline $51-60$ & 56 & |x:| & Enjoy reading a lot & 63 \\
\hline \multirow[t]{2}{*}{$61+$} & 57 & |14) & Quite enjoy readiny & 56 \\
\hline & & & Not keen on readin & 50 \\
\hline LRC staff & 81 & {$[2]$} & & \\
\hline Admin staff & 63 & $\mathrm{mon}$ & Total & 60 \\
\hline Other staff & 62 & [26] & & \\
\hline Academic staff & 57 & 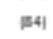 & & \\
\hline Contracted staff & 40 & (15) & & \\
\hline
\end{tabular}

Figure 5: The percentage of respondents who discussed the book with someone else, broken down by broken down by gender, age, ethnicity, faculty (students) or department and role (staff), and by general attitudes towards reading.

$36 \%$ of the student respondents and $14 \%$ of the staff attended at least one of the events (the Nick Hornby talk in September, Welcome Week events, Balloon Debate and in the case the staff the Nick Hornby talk in June 2015 as part of Kingston Connections). Although students and staff who had read the book were much more likely to come to an event there was still a minority who came to an event even if they had not read any of the book. Similarly, while those who thought it a good book choice for The KU Big Read were more likely to come; there were a number of those who did not think it a good choice who came anyway

\section{The book was mostly considered a good choice, especially by the students}

Choosing a book for shared reading is invariably controversial. Feedback from the various editors of Granta involved with the Best of British campaigns (Burford et al, 2013) confirmed that choosing titles for recommendation invariably leads to controversy about which titles should receive this level of attention. Whereas the Best of British Campaign is now seen as a landmark event, at the time Desmond Clarke, Director of the Book Marketing Agency, whose idea it was, received ongoing 
criticism that the books selected 'did not need promoting' and that instead it would be far better to concentrate the resources available on new authors rather than established writers.

Along similar lines, Rose Goddard, World Book Night Programme Manager at The Reading Agency commented:

'A carefully-curated book list, promoted and discussed widely, presents a great opportunity to showcase and recommend brilliant books to new and existing readers alike. Through what is included and left out, it can instigate the kind of lively conversations about books that are vital to our public life.

At World Book Night, we give debut as well as midlist writers the chance to sit alongside more established names on our list of books, which are promoted and then distributed by enthusiastic volunteers to people who don't regularly read on 23 April. In our selection we also strive to achieve a sense of balance and diversity in terms of subject matter, genre, gender, the geographical spread of authors as well as their ethnic background, though as we found in 2015 when selecting the books for the following year's celebrations, striking such a nuanced balance can sometimes be difficult (Goddard, 2015). Because of their selective nature, book lists and recommended reads will inevitably be scrutinised for perceived gaps and omissions, and so become an important vehicle for debate and discussion.'

While controversy may be viewed as a legitimate publicity strategy, fostered in order to engage debate around the project, the response within Kingston to the chosen book was generally positive.

$84 \%$ of students and $70 \%$ of the staff who read at least some of the book quite or greatly enjoyed it (rating it 4+ out of a possible 7); the average scores were 4.9 for the students and 4.3 for staff.

(Staff): What did you think of the title selected?

(Students): Did you think About a Boy was a good choice for the KU Big Read?

(7 point scale:1-not good, 4-reasonably good, 7-very good choice)

$\%$ of respondents, $n($ staff $)=212 \mathrm{n}($ students $)=166$ 
Figure 6: What student and staff responders thought of the title selected for The KU Big Read

Both staff and students were offered the option to provide additional comments. A representative sample of student commented included:

'It was brilliant because it was about a boy starting a new school and feeling out of place so it struck a chord with the new undergraduates. Also it is funny and from a Kingston alumnus so it perfectly encapsulates the essence of a Kingston education. The letter from Nick Hornby himself and his experience of studying was a VERY nice touch!'

'Good choice as I don't usually read books but I gravitated towards this one.'

'The fact it was set in London made it relevant to me moving there. Was an enjoyable story so reading it wasn't a chore or effort.'

'I liked that the book came from a Kingston graduate - I felt inspired seeing how successful it was. I didn't really connect with or enjoy the book though but I guess that's just my taste.'

'I'm not sure how the story related to new students at Kingston University.'

Staff comments were more polarised. There was some general support for the book chosen:

'Good choice, enjoyable and easy read. Just what is needed.'

'a simple read so not too challenging, which perhaps makes it dull to some but accessible to many'

Others commented on the implementation of the scheme:

'I think it was a great initiative already. Not much that could be improved from my point of view. More events to go along to and maybe discussion groups at lunchtime. Was a great way to start conversation, especially as a new member of staff.'

'Ensure it is built in, be more assertive. Also positive examples from this year would help.'

'accessible, good as a way of gently introducing international students to the 'liberalness' of UK culture'

'I enjoyed it and it's an easy read and "way in" for students. However, colleagues were dismissive - they wanted a title which was less "male"' and less "white" to appeal to student diversity.'

Some comments showed a lack of awareness about what had already been provided:

'Maybe the author could do a guest lecture which relates the book to some academic disciplines?'

In fact the author had given talks at Kingston twice, and the balloon debate had offered the opportunity to consider how the book related to academic disciplines taught at Kingston. 
A vociferous minority commented negatively on the choice of the book:

'Very unrepresentative for our student body, and especially disappointing given the recent work we have been doing on BME attainment and retention. Also disappointing that the English Literature department was not consulted or included in this event.'

'Too white, middle class, north London'

While colleagues in English Literature had been circulated with information and asked to take part in the same way as every other department in the university, to create a truly cross-organisational feel it was important to ensure that ownership was widely felt and not located in any specific department. A colleague from English Literature did however take part in the balloon debate.

Frustratingly, there were also comments that showed participation had been blocked:

'I was eager for us to include it and thought we should do so at induction or at the first Level Four (first year) tutorial but most of my colleagues had not read it and did not believe the new students would have read it so it was voted against at a meeting.'

\section{There was strong support for the initiative as a whole; students were particularly positive}

$86 \%$ of students and $74 \%$ of staff thought the initiative helpful for new students at Kingston University (awarding it a score of $4+$ out of a possible 7).

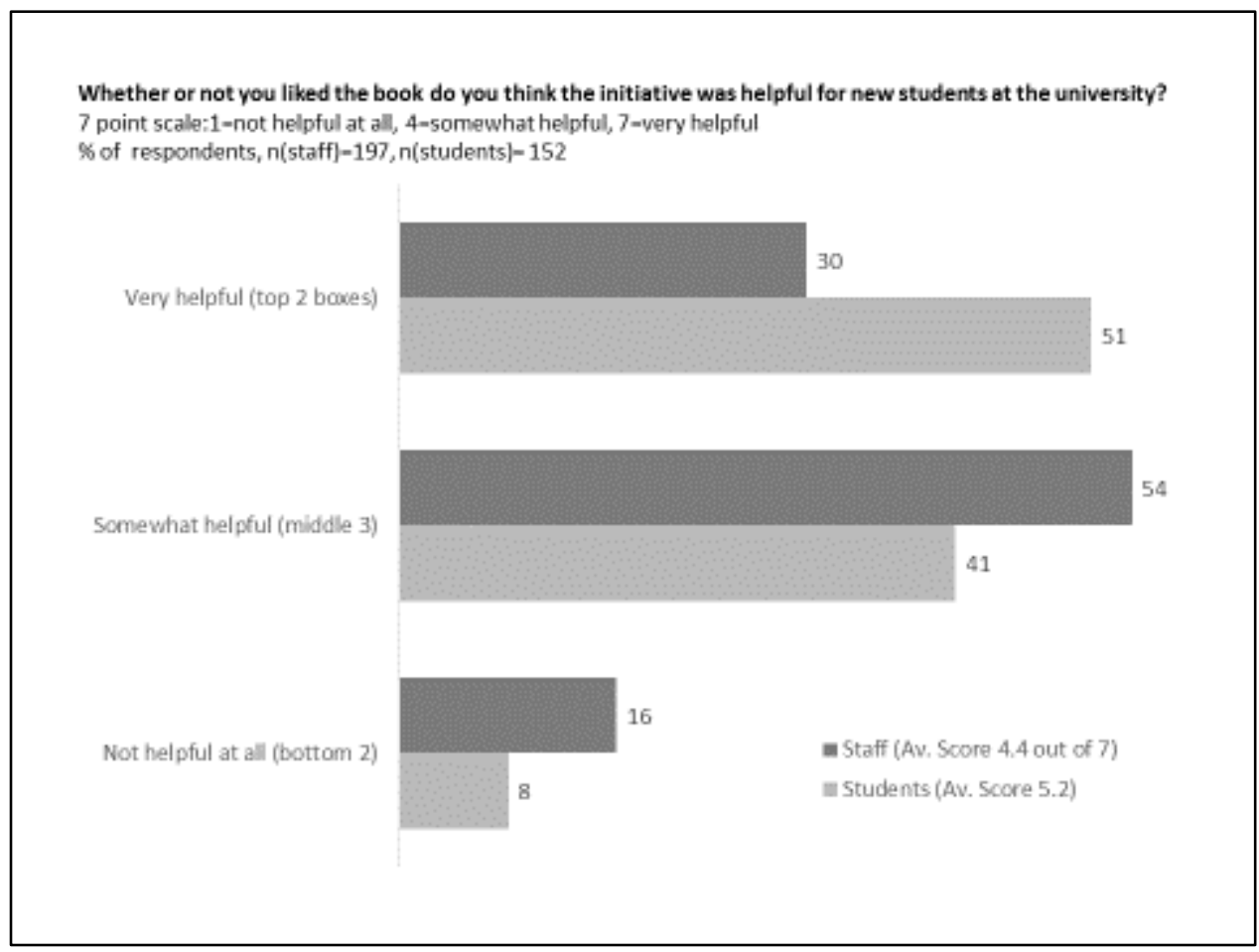

Figure 7: How helpful student and staff responders thought The KU Big Read was for new students at university.

When given the opportunity to comment on the benefits and barriers to involvement, a wide range of benefits were communicated, but also some perceived barriers. 
Benefits included the advance welcome offered to students, and their ability to feel part of the university before they arrived. The scheme was perceived as an ice-breaker, offering the opportunity to bring people together, particular those with similar interests and hence reduce alienation. The scheme was seen as helping to prepare potential students for university, a scheme which was stimulating and made people think, and which increased understanding of university. It offered the opportunity to read a British writer and to learn more about Britain. Verbatim comments included:

'It helps new students to:- 1 . fit in, have something in common and to talk about with everyone else 2. meet new people and develop friendships 3. improve academic skills and broaden one's school of thought'

I'm an introvert but I love talking about books. Talking about a book helps to start a conversation when getting to know new people.'

'Something to talk about which breaks the ice a bit.'

'Makes students read and think prior to university'

'Common topic to discuss, feel included and involved, encourages literacy'

'You immediately have a connection to university and other students.'

'It means that they feel like they are a part of something before starting university.'

The main barriers to involvement were lack of time and the pressure of other things to do, including university work. Shyness and embarrassment were seen as barriers to involvement as were apathy and a language barrier. Not liking reading was also seen as a barrier to involvement. Verbatim comments on barriers to involvement included:

'Being shy and not bothered'

'Time'

'Embarrassment'

'Some people don't read for pleasure and therefore they won't read book.'

'General apathy among students.'

'1. Pressure and anxieties of being in University 2. Not given as much weight or value by the University, so students are not bothered really. Maybe if it's incorporated a lot more into our fields of study like we did with our Communication Module and/or maybe set an exercise/ test and grade it, then maybe students would be compelled to participate.' 
'The very act of having to attend group sessions, when you're an international student all alone.'

Overall, there was enthusiasm from staff for continuing the Big Read with $77 \%$ of respondents fairly or very interested to take part again next year (top three options on a scale of 1 to 5). $39 \%$ were keen or very keen and $36 \%$ reasonably so.

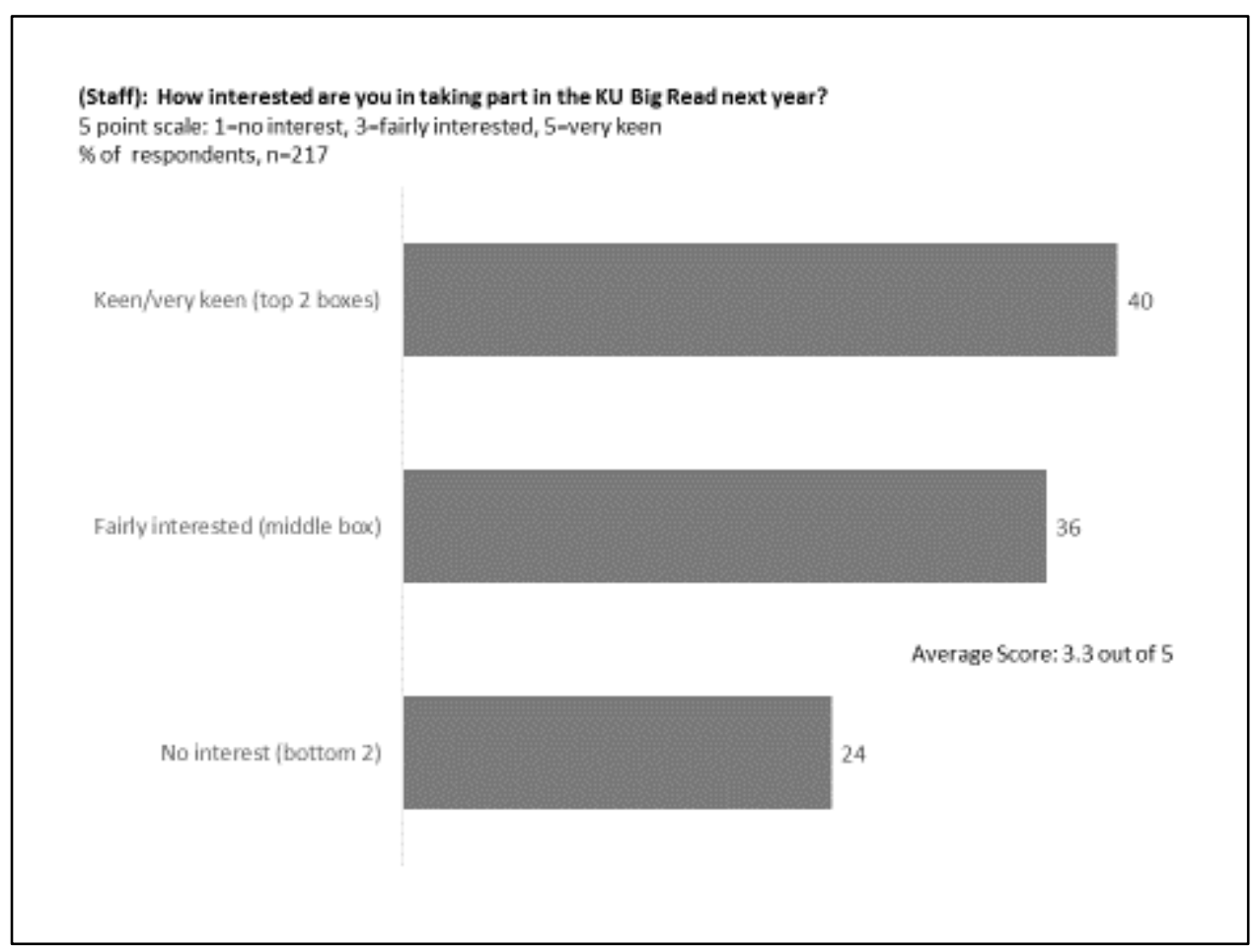

Figure 8: Staff interest in being involved in The KU Big Read next year.

\section{Learnings for next time}

The project has now been established both as a research project and as a key element of Kingston University's outreach and retention programme. Experience from the first Big Read showed that a number of issues need careful consideration next time. In particular, it was observed that:

\section{The timing for making books available to academics must be carefully considered}

The availability of books and the timing of the associated announcement were particularly important to academic staff. Some had departed for the summer to work on their own research before the books were available and so were less aware of associated developments or events. While it would be difficult to make the book available much earlier, given the processes involved in creating a bespoke edition, arguably this lack of awareness will be mediated by a higher profile for the initiative as a whole and the fact that in subsequent years this will no longer be a new scheme; both will likely assist its embedding within the consciousness of academic staff.

\section{It is important to include all students}

The importance of including all students involved with $\mathrm{KU}$ rather than just undergraduates emerged as a factor of significance to the university community. Frustration was identified within the Masters student community that their opinions are not sought more often, and they are not included in 
many of the monitoring processes that assess UK universities. For most Masters students their place of study is the last academic brand to appear on their CV and it is consequently unsurprising that they like to feel involved and valued.

\section{Consideration needs to be given to the inclusion of international students}

In 2015 international students were not posted a copy for a number of reasons. Firstly significantly more international students apply than enrol. Whereas this could mean that copies could be sent to those who do not subsequently come to Kingston, the opposite view could also be taken, and that as students have expressed an interest in the university, their decision may be positively influenced by the receipt of a book.

Similar schemes in the US have concluded that pre-arrival shared reading can impact on potential students' decision to enrol, and so sending a book to a student who has at least expressed an initial interest in the institution could be a good investment. There are international students whose places are coordinated through agencies, and thus direct contact is not possible. But again, sending books to agencies may influence the decision both recommended and taken. Finally there is the language issue, and international students for whom English is not their mother tongue could be a group both significantly able to benefit from prior language practice and needing longer to read the book. Both lead to conclusions about when it would be best sent. It was noted that a question should b e included in future surveys about whether the student responding is an international student.

\section{A more inclusive method of choosing the book is required}

There were many comments about the choice of book. The 2015 title was chosen quickly in order to progress the scheme, but it was agreed that for a repetition of the scheme, a more engaged and inclusive method of discussion and selection would be needed.

\section{Books need to be sent promptly to students who accept a place through clearing}

The books need to be sent promptly to students who have accepted a place through clearing. These students have the least time to read it before they arrive, but they may also be least familiar with the institution - as it probably not been their initial choice. It follows that early receipt of branded item might further augment their decision to enrol.

\section{Conclusion}

In conclusion, the responses to the scheme from within the University were mostly very positive and there was much greater staff involvement than had been anticipated. Moreover The KU Big Read also offers significant potential for impact within the wider community. Information about the first Big Read was spread to the community via Kingston Connections, and the open event with Nick Hornby to which the wider community was invited to participate, with a follow up session to discuss how local people might become more involved. There have been positive responses from AimHigher London South ${ }^{2}$ (an outreach organisation aiming to provide teachers with information on access to higher education for those from families with no prior experience of university); The Kingston branch of the University of the Third Age ${ }^{3}$, The Royal Borough of Kingston (the local council are particularly interested in the departmental reading undertaken by KU's Finance Department and in setting up

\footnotetext{
${ }^{2}$ http://aimhigherlondonsouth.org.uk/

${ }^{3}$ http://www.kingstonu3a.org.uk/
} 
shared reading within the borough offices), the council agencies that reach out to local schools and libraries (there are discussions about how the scheme could be supported and spread).

Within Kingston University, staff involved in developing student engagement are considering whether book discussions could feature in community relationship schemes, designed to build local relationships around areas of common ground rather than focus on problems, as and when they arise. The student press, notably The River which is available online and in print, have found that features on The KU Big Read get strong noting, and are keen to build on material that appeals to their readership. Overall, the project has considerable potential for academic diplomacy, building relationships with key educational and local stakeholders in the university's relationships and very cost effective marketing for the institution. Joining up staff and students from across the institution and providing common ground.

The 2015 book was chosen quickly in order to enable the scheme to proceed. For the 2016 scheme the involvement of the wider community has been sought. All KU staff and students were asked for suggestions; more than 100 were received. A new SADRAS team was set up for Big Read 2 and, again working with students, the various factors were considered that would make a good choice, weighted for which mattered most, and developed an associated algorithm. This has preserved the cross-university character of the project. The process of making a choice for KUBR2 will be examined in a subsequent paper.

Finally, it is important to consider how the research project that is integral to The $K U$ Big Read can be extended, and to this end thought is being put into developing the project within a second university, in order not only to extend the benefits for student engagement and employability but to compare outcomes and impact within a similar university. A proposal is under development to work with an institution of similar size and with a similar ethos and demographic profile in certain respects but with a very different ethnic profile, in the process creating a research population of a really significant size and ensuring greater value for the allocated resources.

\section{Bibliography}

Baverstock, A. et al (2016). 'The Implementation of a Shared Reading Programme in a University: A case study.' Logos (in press).

Baverstock, A. (2016). Measuring the success of The KU Big Read

http://www.unialliance.ac.uk/blog/2016/06/29/measuring-the-success-of-the-ku-big-read/

Burford, W. et al (2013). Then and now: Granta's best young British novelists The Guardian blog. https://www.theguardian.com/books/2013/apr/06/then-now-granta-best-novelists

Ferguson, M., (2006). 'Creating Common Ground: Common reading and the first year of college', Peer Review, 8 (3), pp. 8-10

Frostick, T. (2015). Kingston University's Big Read

http://www.unialliance.ac.uk/blog/2015/09/29/kingston-universitys-big-read/

Goddard, R. (2016) http://www.thebookseller.com/blogs/why-world-book-night-2016-wasnt-ableinclude-bame-authors-317380. Accessed: $19^{\text {th }}$ July 2016 
Golden, S. (2012). Inside Higher Education. [ONLINE] Available at:

https://www.insidehighered.com/news/2012/01/11/mla-session-first-year-common-readingprograms. [Accessed 31 March 2016].

Markoff, J. (2008). 'The Passion of Steve Jobs' January 15, 2008

http://bits.blogs.nytimes.com/2008/01/15/the-passion-of-steve-jobs/

Penguin (2015). http://penguinpartnerships.co.uk/kingston-university-s-big-read.html Accessed 8th July 2016

Reading Agency and BOP Consulting (2015). Literature Review: The impact of reading for pleasure and empowerment. Available at:

http://readingagency.org.uk/news/The\%20Impact\%20of\%20Reading\%20for\%20Pleasure\%20and\%2 OEmpowerment.pdf (Accessed $9^{\text {th }}$ October 2015).

Twiton, A., (2007). 'Common Reading Programs in Higher Education', Patricia Lindell Scholarship research project https://gustavus.edu/library/Pubs/Lindell2007.html

Websites reporting on pre-arrival shared reading within marketing communications:

https://gobigread.wisc.edu/

http://homepages.gac.edu/ fister/onebook.html

https://gustavus.edu/library/Pubs/Lindell2007.html

http://www.herts.ac.uk/connect/common-reading-programme

https://gobigread.wisc.edu/

http://homepages.gac.edu/ fister/onebook.html

http://www.herts.ac.uk/connect/common-reading-programme 